\title{
Prototype Design Of Chicken Meat Cutting Tool
}

\author{
Laurence $^{1,{ }^{*}}$, Natalia Hartono ${ }^{1}$, and Clara Alverina Setiawan ${ }^{1}$ \\ ${ }^{1}$ Industrial Engineering, Faculty of Science and Technology, University of Pelita Harapan, Indonesia
}

\begin{abstract}
The main thing the chicken skewers owners do is cut the meat into blocks. However, to produce a cubical meat shape is not an easy task and takes a long time. Therefore, it is necessary to design a tool to help the chicken skewers business owner to cut the chicken breast faster. The purpose of this research was to design an ergonomically chicken meat cutting tool to produce cubical chicken meat in large quantities so that the work can be completed in a shorter time. The planning and product development stage of this research was based on Ulrich and Eppinger steps from phases 0 through 4 . After that, a prototype evaluation was performed. The conclusion of this research was that the tool successfully worked as the design intended. The maximum cutting yield is 225 pieces, 15 times faster, suitable for half-frozen chicken meat, and the evaluation results show a good performance rating. Overall, most of the respondents $(87.5 \%)$ were pleased with this tools, shown by $57.5 \%$ choose a smiling face and $30 \%$ show a big smiling face as their feeling of satisfaction after trying the gamma prototype.
\end{abstract}

\section{Introduction}

Chicken skewer business categorized as a micro business where the maximum profit is Rp.300 million per year according to the constitutional law number 20, the year 2008 and also categorized as a home industry because at average there are 1 to 4 workers. This study starts with the observation in Tangerang area where there is a lot of chicken skewers business. When the process of making skewers was observed, it is clear that the main process is to cut the meat and put onto skewers. However, to produce a cubical meat shape is not easy and takes a long time. The preliminary information gathering was done with talking informally with several skewers business owner in Tangerang area and it is found that they need a tool to cut the chicken breast fillet faster.

There is an automatic chicken cutting machine that can cut chicken meat into blocks but the price of such machine is expensive and it means a large amount of investment needed to start the chicken skewer business. Small companies have scarce resources that disrupt them to innovate [1]. Tools and equipment help to perform a task that not easily perform in more efficient way and ergonomics should be involved in the design to ensure safe and effective operation [2]. Therefore, it is necessary to design a manual chicken meat cutter to help micro business and home industry so they can reduce the investment of expensive machine to cut chicken meat faster than using knife only. The purpose of this research was to design

\footnotetext{
*Corresponding author: laurence.fti@uph.edu
} 
ergonomically chicken meat cutting tool to help the work of skewer business owner to produce cubical chicken meat in large quantities so that the work can be completed with a shorter time.

\section{Scope and Constraint}

This research collected data from observation and interview to skewer business owner at Tangerang area from August to November 2017. The knife size was designed to cut chicken breast meat to $2 \times 2 \mathrm{~cm}$ size and can be only used to cut boneless chicken meat or chicken breast fillet. The steps from Ulrich and Eppinger until gamma prototyping due to financial constraint.

\section{Methodology}

The research starts with an identification problem with skewer business owner who needs a lot of preparation and the most time consuming was cutting the chicken meat to shape cubical. Product ideas are based on customer problem and become the heart of the concept generation process [3]. Then, the cutting tools for this needs were searched and continue with an interview with several skewer business owners to gather preliminary data and preliminary voice of customer (VOC). After that, the purpose of this research was established.

Theory of product design and development from Ulrich and Eppinger was used for this research because it provides a step-by-step approach thus the methods are structured and suitable as a starting point for continuous improvement of the product. Ulrich and Eppinger's methods consist of phase 0 to phase 5 [4]. Phase 5 is production ramp-up, and this research until prototyping, so this research were from phases 0 to 4 , which depict in Fig 1. Finally, the conclusion and suggestion for further research were made.

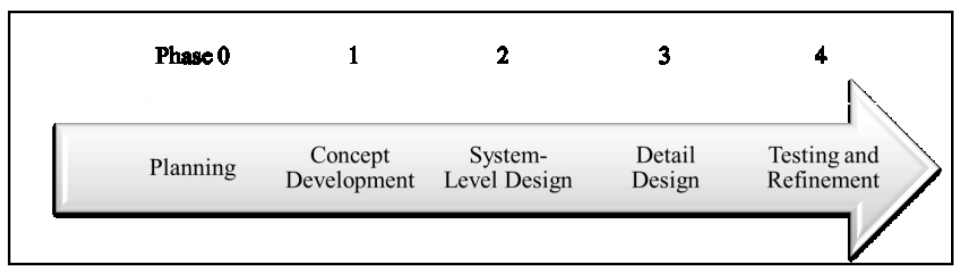

Fig 1. Phases in this research

\section{Product Design and Development}

The phase 0 to phase 4 were explained with detailed in this section.

\subsection{Phase 0}

At zero phase, there is the five-step process: identify opportunities, evaluate and prioritize projects, allocate resources and plan timing, complete pre-project planning, and reflect on the results and the process. Identify opportunities has been done through observation and interview to skewer business owner. The second step is to evaluate and prioritize the project. As this project has focused on designing cutting tools, the competitive strategy used was customer focus, where researchers assess the customer needs and preference of 
end users. Resource allocation and plan timing in this research were using budget under 2 million rupiah and the prototype plan to finish in November 2017.

The next step was complete pre-project planning where the guidance for product development was written in a mission statement that informs the product description, benefit proposition, key business goal, target market, assumption and constraints, and stakeholders. Product description dan benefit proposition was a manual cutting tool that can cut cubical chicken breast meat in large quantities. Not only skewer business owner but also catering can use the same tool to cut vegetables and fruit. The key business goal that the product will be launch at 2018 with primary target market is skewer business owner and secondary target is catering business owner. Assumption and constraints in this product development are this product is designed to cut boneless half-frozen chicken meat and other meats like duck, fish, beef and can cut soft vegetable and fruit. The stakeholders are all the groups of people who are affected by the product's success or failure [4], that are skewer business owner, catering business owners and the design team. The final step in this phase is reflected in the results and the process and it is decided that this idea can be continued to phase 1 .

\subsection{Phase 1}

Phase 1 is a concept development that consists of identifying customer needs, product specification, concept generation, concept selection, and concept testing. The first steps in phase 1 are identifying customer need with gathering raw data from customers (skewer business owner in Tangerang area) using questionnaire and interpret the raw data in terms of customer needs, followed by organize the needs into a hierarchy, establish the relative importance of the needs and finally reflect on the results and the process. The product specification use data from the previous step and interpret the raw data into the voice of customer (VOC) and establish the relative importance of the needs using Quality Function Deployment (QFD) that consists of House of Quality (HOQ) 1 and HOQ 2. The next step is comparing the design with competitor products and reflect on the results and the process.

From the HOQ 1 table, the highest importance level was tool durability test and product usage test $29.1 \%$ and $24 \%$ respectively. The result of HQO 2 shows that the most important part of this tool is the knife shown by the level of importance by $53.2 \%$. Two benchmark competitor product is skewered machining chicken meat lamb and automatic chicken skewer machine. The weaknesses of first competitor products are it needs several cuts and the results are too dense between the meat, where the skewer business owner usually want the meat not too dense. The second competitor needs electricity and expensive.

The next steps are concept generation. A product concept is an approximate description of the technology, working principles, and form of the product [4]. This research develops several concepts that follow the customer needs and target specification from the previous steps. The concept is usually expressed as a sketch or a rough three-dimensional model [4]. The concept generation steps are clarified the problem, search externally, search internally, explore systematically, and reflect on the solutions and the process. The first step is to make a description of the product, that the cutting tool will cut chicken meat faster, in large quantity and has a $2 \times 2 \mathrm{~cm}$ shape, made from food-grade stainless steel to ensure safety in kitchenware, equipped with a handle to grip the tools, will have square shaped container. The tools designed to cut the half frozen chicken meat because based on the search on the interviews with skewer business owner and catering business owners, a half frozen meat will give better cutting results because of its solid meat structure. In addition, data from the USDA (United States Department of Agriculture Food Safety and Inspection Service) said that bacteria in chicken meat will grow rapidly at temperatures between $4.4^{\circ} \mathrm{C}$ and $60^{\circ} \mathrm{C}$ [5]. The external search steps were a search for the patent of chicken meat cutting tools and 
the results are there is no similar design. The search was at the Indonesian government website of Directorate General of Intellectual Property [6]. The internal search step using brainstorming to explore the idea and make sketches. The idea is to combine the cutting board and a kitchen knife. The process of external and internal search results in many concept fragments and need to organize and synthesized using concept combination table. This process resulting 4 alternative concepts and can be seen in Fig 2.

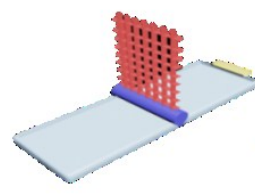

1

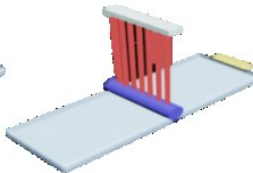

2

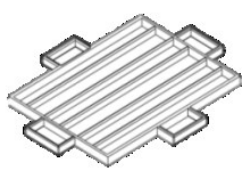

3

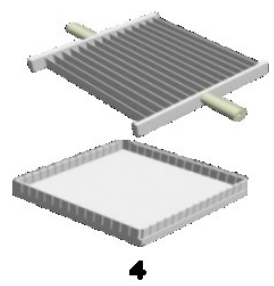

Fig 2. Four alternative concepts

After that, reflect on the solutions and the process shows that this concept can continue to the next step. The next step is concept selection and concept testing, and in this research using external decision to choose among concepts. The four concepts were showed to the skewer business owner and catering business owners and $50 \%$ of them choose number 4 , so this concept was chosen.

\subsection{Phase 2}

Phase 2 System Level Design consists of product architecture. Product architecture is the assignment of the functional elements of a product to the physical building blocks of the product [4]. The cutting tools are simple without many parts so that the product architecture is the same as the product description.

\subsection{Phase 3}

Detail design in this third phase consists of a specification of the shape and material of all components of the product, material and planning of product process making, and prototyping. Based on interviews and observations, the skewer business owner age ranged from 21-45 years. This data used to determine the size of the handle to get an ergonomic product. The dimensional data was obtained from the web antropometriindonesia.org [7]. To determine the size of the handle, the data use the bottom of the percentile, that is the 5 th because the handle is a part that must be able to be grip so the size used is the minimal dimension size so the people with small or large hand sizes will be able to hold the handle. It is known that the size of the hand for the fifth percentile is $16.5 \mathrm{~cm}$ and for the width of the hand is $9.09 \mathrm{~cm}$. The handle should be designed to have large contact surfaces so the force distributes over a larger area [8]. Therefore, the size of the handle is $10 \mathrm{~cm}$ in length with a diameter of $2.5 \mathrm{~cm}$. The handling also has a similar resemblance to the size of a general motor handlebar. Fig 3 shows the summarize of product detail design. This cutting tool would suitable for both right and lefthanders person and for both male and female because it is designed with two handles so the force will be smaller compared to just one handle. The design follows the principle of hand tool design that is design for use by either hand, for an individual user, and design for a power grip [2]. 


\begin{tabular}{|c|c|c|c|c|c|c|c|}
\hline Parts & Function & Material & Dimension & Weight & \begin{tabular}{|r|}
$\begin{array}{c}\text { Make } \\
\text { /buy }\end{array}$ \\
\end{tabular} & Picture & Quantity \\
\hline Cutting board & $\begin{array}{l}\text { as a place to lay } \\
\text { chicken meat }\end{array}$ & $\begin{array}{l}\text { cutting board } \\
\text { wood }\end{array}$ & $34 \times 34 \times 5 \mathrm{~cm}$ & $1.5 \mathrm{~kg}$ & make & & $1 \mathrm{pcs}$ \\
\hline $\begin{array}{l}\text { Side of the } \\
\text { cutting board }\end{array}$ & $\begin{array}{l}\text { become a support for } \\
\text { the cutting board }\end{array}$ & $\begin{array}{l}\text { cutting board } \\
\text { wood }\end{array}$ & $36 \times 36 \times 7 \mathrm{~cm}$ & $0.25 \mathrm{~kg}$ & make & & $4 \mathrm{pcs}$ \\
\hline Knife & to cut & stainless steel & $\begin{array}{l}38 \mathrm{~cm} \text { with } \\
3 \mathrm{~mm} \text { thickness }\end{array}$ & $0.25 \mathrm{~kg}$ & make & & $14 \mathrm{pcs}$ \\
\hline $\begin{array}{l}\text { Blade } \\
\text { connection }\end{array}$ & $\begin{array}{l}\text { as connection between } \\
\text { knifes }\end{array}$ & stainless steel & $33 \mathrm{~cm}$ & $0.25 \mathrm{~kg}$ & make & & $2 \mathrm{pcs}$ \\
\hline Holder & $\begin{array}{l}\text { for easy handling at the } \\
\text { cutting process }\end{array}$ & stainless steel & $\begin{array}{l}10 \mathrm{~cm} \text { long with } \\
\text { diameter } 2.5 \\
\mathrm{~cm}\end{array}$ & $0.25 \mathrm{~kg}$ & make & & $2 \mathrm{pcs}$ \\
\hline
\end{tabular}

Fig 3. Refining Specification and Parts

After the specification, the next step is to make a prototype. Prototyping is the process of developing such an approximation of the product [4]. There are two prototypes in this phase. Prototype alpha was the first prototype made from the plastic board. In making this prototype, the handle was different than the planning due to the difficulty to make rolling handlebar. This prototype making was used to know the big picture of the product designed. After analyzing the alpha prototype, the beta prototype is made from $3 \mathrm{~mm}$ medium-density fibreboard (MDF) using laser cutting to the actual dimension of the design. Using prototype beta, an internal evaluation is performed to identify the required engineering changes for the final product.

\subsection{Phase 4}

Evaluation of the previous prototypes shows that the cutting tools can work as the design intended, and the step progress to phase four, testing and refinement. The gamma prototype was build to be used as trial and evaluation to the end users. In this prototype, the material used for the knife and handle was iron plates while for the container was made from wood. The shape of this prototype is the same with a beta prototype but this prototype had different sizes and shapes of the handle. The handle was shaped like a tube with the length of $10 \mathrm{~cm}$ and diameter of $2.5 \mathrm{~cm}$ as the design in the previous phase for easier grip. The process of making the gamma prototypes will be the same with the actual product, but with different material for the knife. Prototype knife made from iron while the actual product from stainless steel. The process starts with pattern making, measurement, cutting the materials, polishing, made the knife blade using milling and grinding machine, assembling and final inspection. Figure 5 shows the picture of the gamma prototype.

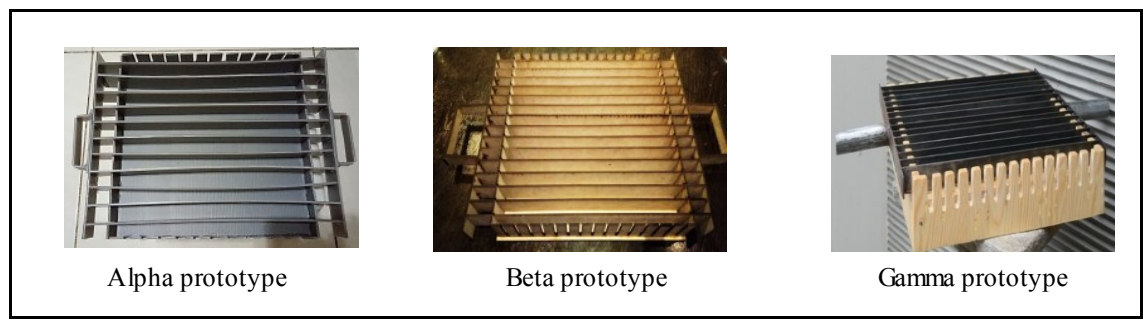

Fig 5. Prototypes

The testing involved 40 users (29 skewer business owner and 11 catering business owner) to test the product and followed by evaluation using a questionnaire. The results are the cutting board container can hold to $10-12$ boneless chicken breast in one cut and 
produces 225 cubical $2 \times 2 \mathrm{~cm}$ shaped. This test was compared with cutting with a knife and the results show that to cut with knife 10 boneless chicken breast need 685 seconds and with this gamma prototype only need 45 seconds, which is 15 times faster using this cutting tools. The questionnaire adapted from Ulrich and Eppinger to evaluate the quality of the design with rate 1 to 5 from low to high valuation. At the end of the questionnaire was a question about the overall satisfaction feeling of the respondent to this gamma prototype. The results show that on average, respondents give a performance rating of 4 that shows that overall the tools have good performance rating. The respondents felt about the tools showed that $12.5 \%$ feels neutral, $57.5 \%$ happy, and $30 \%$ feel very happy with the products.

\section{Conclusion}

The process of making the cutting tools was done using Ulrich and Eppinger phases until prototyping. The evaluation of gamma prototype shows that this tools can cut as the design intended, which are 15 times faster, cut in cubical shaped with maximum cutting yield is 225 pieces, has performance rating of 4 which means good performance and most of the respondents were pleased with the products shown by $57.5 \%$ choose happy face and $30 \%$ choose big smiling face as their feeling of satisfaction after trying the gamma prototype.

\section{Recommendations}

This research shows that not only a sophisticated product can use the phase from Ulrich and Eppinger, but also simpler products. The phases direct the product designer to focus and in practical implication will be useful to people without product design background who wants to make products based on the voice of the end customers.

The research can add economic analysis to evaluate if this gamma prototype could be developed further to be sold.

\section{References}

1. L. Löfqvist, Product Innovation in Small Companies: Managing Resource Scarcity Through Financial Bootstrapping, Int. J. of Innovation Management 2121750020 (2016)

2. M.R. Lehto, J.R. Buck, Introduction to Human Factors and Ergonomics for Engineers (Taylor \& Francis Group, New York, 2008)

3. M. Crawford, A. Di Benedetto, New Product Management (McGraw-Hill Irwin, New York, 2011)

4. K.T.Ulrich, S.D.Eppinger. Product Design and Development. Sixth Edition (McGrawHill Education, New York, 2016)

5. United States Department of Agriculture Food Safety and Inspection Sevice. Chicken from Farm to Table. https:/www.fsis.usda.gov/wps/wcm/connect/ad74bb8d-1dab49c1-b05e-390a74ba7471/Chicken_from_Farm_to_Table.pdf?MOD=AJPERES (retrieved September 2017)

6. Direktorat Jendral Kekayaan Intelektual (Directorate General of Intellectual Property) www.pdki-indonesia.dgip.go.id (retrieved August 2017)

7. Antropometri Indonesia Anthropometry) http://antropometriindonesia.org/index.php/detail/artikel/4/10/data_antropometri (retrieved September 2017).

8. M.S. Sanders, E.J. McCormick, Human Factors in Engineering and Design (McGraw Hill, Singapore, 1992) 